\title{
INFRARED STIMULATED LUMINESCENCE AND THERMOLUMINESCENCE DATING OF ARCHAEOLOGICAL SAMPLES FROM TURKEY
}

\author{
NIYAZI MERIÇ ${ }^{1}$, M. ALTAY ATLIHAN ${ }^{1}$, MEHMET KOŞAL ${ }^{1}$, ÜLKÜ RABIA YÜCE ${ }^{1}$ \\ and AYKUT CINAROGLU ${ }^{2}$ \\ ${ }^{1}$ Ankara University, Faculty of Engineering, Department of Engineering Physics, \\ 06100, Beşevler - Ankara, Turkey. \\ 2 Ankara University, Faculty of Letters, Department of Archaeology, \\ 06100, Sihhiye - Ankara, Turkey.
}

\begin{abstract}
In this study, the potential of Infrared Stimulated Luminescence (IRSL) and thermoluminescence (TL) for dating the archaeological samples (pottery sherds and soil sample adhered to surface of human bone) which were taken from a Necropolis was investigated. Archaeological sherds taken from Nusaybin (Mardin, Turkey), an archaeological site of archaic and Hellenistic period (from $330 \mathrm{BC}$ to $30 \mathrm{AD}$ ), were dated. Samples were prepared by the fine grain technique and paleodose values were estimated by using multiple aliquot additive dose (MAAD) and single aliquot regenerative dose (SAR) procedures. The annual doses of uranium and thorium were determined by using the low level alpha counter. The potassium contents, which have no alpha activity, were determined by XRF equipment. The average age of the sherds were found to be $2375 \pm 170$ years which is in good agreement with the archaeological evidence involving architecture of castle wall, Necropolis and column sherds in the vicinity of the site.
\end{abstract}

Keywords: IRSL, TL, ancient pottery, dating, Necropolis.

\section{INTRODUCTION}

Thermoluminescence (TL) and Infrared Stimulated Luminescence (IRSL) are the two common methods for dating soil sediments and heated objects such as pottery and for environmental dosimetry (Zuchiewicz et al., 2004; Tanır et al. 2004; Kıyak and Erturaç, 2008; Moska et al., 2008; Atlihan and Meriç, 2008; Madsen and Murray, 2009).

Sediments and some archaeological artifacts contain polyminerals composed of crystal structure. When these minerals extracted from a buried material that are subjected to ionizing radiation (alpha, beta, gamma) from radionuclei (i.e. $\mathrm{U}, \mathrm{Th}, \mathrm{K}$ ) in the surrounding soil, this natural irradiation causes ionization of valance electrons and creates electron/hole pairs. Then these free electrons and holes are trapped at pre-existing lattice defects within the crystal structure of the mineral. When this crystal is subsequently excited by heating or by exposure to light, electrons can be released from the traps and recombine with the holes. The recombination energy is emitted as thermoluminescence and Infrared Stimulated Luminescence respectively (Aitken, 1985).

Absorbed dose by the buried material is proportional to luminescence quantity that is proportional to trapped charge concentration; this can be related to the time in which the crystal is subjected to ionizing radiation and called equivalent dose (ED). Dose rate (DR) is the dose that sample received per unit time (a or ka). This dose rate is calculated from measurements of the radioactive elements $(\mathrm{K}, \mathrm{U}, \mathrm{Th})$ within the material and its surroundings and from the radiation dose rate from cosmic rays. The age of the material can be calculated by the equivalent dose (ED) divided by the annual dose rate (DR). 


\section{INITIAL OBSERVATIONS ON NECROPOLIS HISTORY AND ARCHITECTURE}

It is a known fact that the roots of the rock cut and the grave sites located at eastern Turkey extends their existence to $9^{\text {th }}$ century BC. Many Urartu kings' tombs have been discovered in the region. These tombs were built as underground chambers (Şenyurt, 2006). The elaborate tombs appear to have been built for a single person. However, in today's Nusaybin's Koruköy village one can observe cemeteries that house the remains of many people that has been buried in the same place over many centuries.

Upon further study of the tombs, one can identify that they were all based on basic simple structure that included an entry, an exit and main tomb chamber. The main structural elements include the dromos i.e. entrance passage that lead into the main chamber, doorway leads into the tomb chamber and the main tomb chamber. Over time, the Niches carved into the exterior wall of the tombs disturbed the original structural integrity of these structures. The remains of the original occupant of the tomb were left inside the tomb chamber as new niches were carved depicting information on newly deceased person.

The study was able to gain entrance only to one of the eight tombs discovered in Kuruköy. Unfortunately the tomb appears to have been abandoned for a long time. Therefore the original artifacts left in the tomb have either been lost or destroyed over the time. However further study of the ceramic pieces that adorned the dromos and archaeological investigation of the ruins of a fort nearby the tomb revealed that the tomb may have been in use as early as $3^{\text {rd }}$ or $2^{\text {nd }}$ century BC.

\section{SAMPLING}

\section{Sampling Site}

In this study, we have investigated whether a necropolis located in the Nusaybin/Mardin/Turkey (Fig. 1) is a new or old grave. Prior to the construction of the CeyhanBaku pipeline necessary archaeological and geological studies and surveys were conducted. During these studies a number of necropolises were discovered. A similar necropolis was discovered in Nusaybin-Mardin by the indigenous people of the area. The spotlight shined on these new discoveries by the local as well as the national media, stimulated further studies of the region and the necropolises. Urartu reign has ruled the region during late $9^{\text {th }}$ century BC to late $7^{\text {th }}$ century BC. However, Assyrian Empire has ended the Urartu reign towards the end of $7^{\text {th }}$ century BC. As the Assyrian Empire weakened its hold on region, the Hellenistic rule took hold as early as 330 BC. The Hellenistic reign continued until 30 AD. Following the Hellenistic reign, the region was ruled by Eastern Roman Empire which was followed by the Byzantines Empire. Towards the end of the Byzantines reign, the region welcomed the Armenian and Turkish settlers. The Turkish rule which started with Great Seljuk Empire in the $11^{\text {th }}$ century AD continues until today (Şenyurt, 2006).

The other objective of this study is to test the applicability of IRSL dating methods to soil samples adhered to the surface of human bone collected from the Necropolis. Therefore it has been investigated also whether soil sample (lab code: NSB4) adhered to surface of human bone can be dated using IRSL dating. Although IRSL dating of soil sample which adhered to surface of human bone is not a well known procedure in sediment dating, it is considered that the age of this soil sample can indicate the date of burial. Therefore, in addition to three pottery sherds (sample's codes: NSB1, NSB2, NSB3), soil sam-

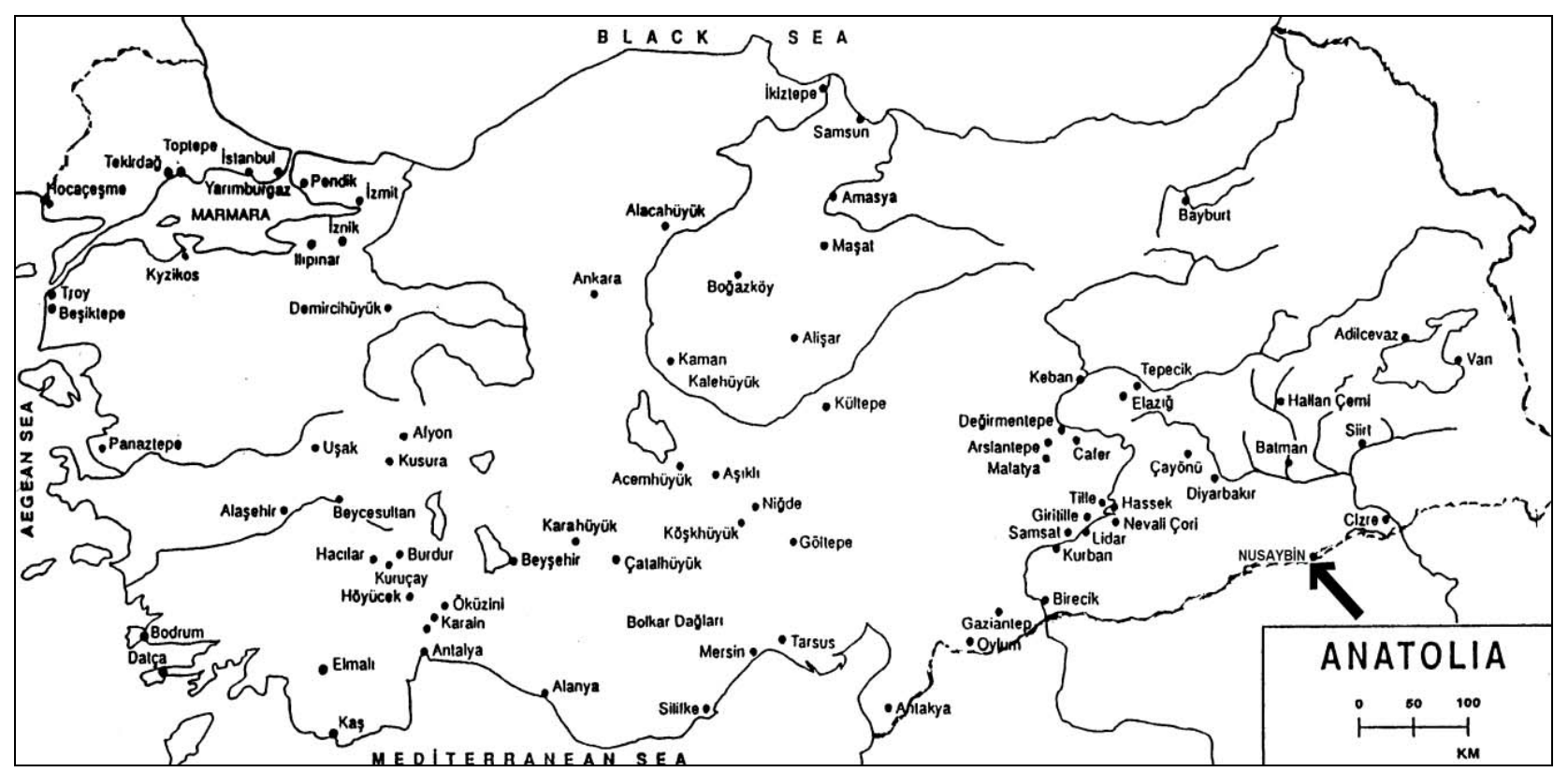

Fig. 1. Map of Turkey with some archaeological sites. 
Table 1. Annual doses from different types of radiation in pottery sherds and soil sample $\left(\mathrm{K}_{2} \mathrm{O}\right.$-the potassium content, $\mathrm{W}$-Saturation Water Content).

\begin{tabular}{lccc}
\hline Sample & $\mathrm{K}_{2} \mathrm{O}(\%)$ & $\mathbf{W}(\%)$ & Annual Dose (mGy/a) \\
\hline NSB1 & $1.23 \pm 0.02$ & $41,05 \pm 0.37$ & $3.42 \pm 0.18$ \\
NSB2 & $1.52 \pm 0.02$ & $38,29 \pm 0.37$ & $3.73 \pm 0.20$ \\
NSB3 & $1.16 \pm 0.02$ & $36,71 \pm 0.37$ & $3.24 \pm 0.17$ \\
NSB4 & $1.14 \pm 0.02$ & - & $3.55 \pm 0.17$ \\
\hline
\end{tabular}

ple (sample's code: NSB4) adhered surface of human bone was collected from the necropolis.

The height of the Necropolis is 2 meters and its area is about 15 square meters. The bone sample together with soil adhered to its surface was taken from 2 meters below the present earth surface. On the other hand, pottery sherds, red color, made from soil, were collected 0.5 meter below the present earth surface. Also some soil material was taken from the same depth to determine the external gamma dose rate to the pottery sherds. All samples were collected at night under faint light circumstance.

\section{Sample preparation and instrumentation}

The outer surface $(3 \mathrm{~mm})$ of the pottery was removed. The outer layer was discarded for following reasons:

- The beta dosage in it is transitional between that corresponding to the sample radioactivity and that corresponding to soil radioactivity;

- There may be a reduced level of luminescence in the outer surface because of the effect of sunlight;

- Soil contamination must be avoided because of its high level of geological luminescence.

Soil sample was obtained from surface of human bone by scraping with a brush. From sawing onwards all operations are carried out in the subdued red light to avoid bleaching effects.

In order not to neglect alpha radiation contribution on natural dose measurements the fine grain techniques is used. The alpha radiation has extremely short range of travel in pottery fabric (about $25 \mu \mathrm{m}$ ) (Aitken, 1998). So, grains less than $20 \mu \mathrm{m}$ in size were used in this work.

All samples were crushed gently. They were washed in $10 \% \mathrm{HCl}$ and $35 \% \mathrm{H}_{2} \mathrm{O}_{2}$ to remove carbonates and organic materials. Afterwards they were washed in distilled water and then were dried and sieved to obtain the size of fine grain $(<20 \mu \mathrm{m})$. Then, the grains were suspended in acetone and deposited on aluminium discs of $10 \mathrm{~mm}$ diameter and $0.5 \mathrm{~mm}$ thickness. Aluminium discs were put in the bottom of small glass tubes; the suspension was put in this tube and with the evaporation of acetone a thin layer of sample was produced.

TL measurements were performed using a Harshaw 3500 reader system whose maximum heating temperature is $600^{\circ} \mathrm{C}$. The Optical Dating System 9010 Reader developed by Spooner et al. (1990) was used. The basic luminescence reader incorporates an IR LED $(880 \pm 80 \mathrm{~nm})$ module based on the design described by Spooner et al. All data were collected using an IRSL add-on unit for the
9010 automated reader, which uses TEMT 484 IR diodes run at $40 \mathrm{~mA}$, giving a power of about $30 \mathrm{~mW} / \mathrm{cm}^{2}$ at the sample. Luminescence was detected using a Thorn EMI 9235 QA photomultiplier tube.

Internal doses from the samples themselves and external dose from the surrounding sediment were determined for pottery samples. After measurements, only total gamma dose rate consisted of that of surrounding sediment and that of sample was calculated by a definite equation dose (Aitken, 1985). Annual doses are presented in the Table 1. Because radioactive potassium does not emit alpha particle, the concentration cannot be determined by low level alpha counter. In archaeological studies, potassium and similar elements are ascertained by using techniques such as ICP-MS, ICP-AES, and NAA. Therefore the potassium content is determined by XRF. Only for contributions from U and Th, "pairs" technique is performed so the dose rate is measured using a 7286 low-level alpha counter (Aitken, 1985). The type of photomultiplier tube used in the 7286 is an EMI 6097 B.

Since the water content of the sample plays an important role on the absorption of the radiation, the saturation water content measurements were performed on pottery sherds. The soil sample was dry, given that the human bones were taken from sealed a stone tomb (Necropolis) underground. So the saturation water content measurement was not performed for soil sample which adhered to surface of the bone. The cosmic ray contribution was taken into account, as in Aitken (1985). For any sample, the fraction of saturation value (F) can be taken as $0.6 \pm 0.2$ or $0.8 \pm 0.2$ according to the region's climatic conditions (Aitken, 1985). Since the pottery sherds were in a covered chamber, $\mathrm{F}$ value was taken as $0.6 \pm 0.2$ considering environmental moisture. The cosmic ray contribution was taken into account, as in Aitken (1985). Alpha dose attenuation factor is determined by means of experimental methods as well as, in restrictive possibilities the value 0.15 can be used (Aitken, 1985). In a similar study, with statistical uncertainty below $6 \%$, the attenuation factors were determined in closes this value (Vieillevigne, 2007). In studies of fine grain polymineral anomalous fading rate is $0-4 \%$ decade (Zink, 2008).

\section{APPLIED METHODOLOGY}

\section{Equivalent Dose Measurements}

Three pottery sherds were taken from the study area. Both TL and IRSL were applied for one of them (NSB1). Only TL was applied for others (NSB2 and NSB3). IRSL was applied for the soil sample (NSB4). Since the saturation dose of this type of material is much higher than the dating dose, dose recovery test was not used in this study.

\section{IRSL}

In order to perform MAAD (Multiple Aliquot Additive Dose) procedure a lot of discs are used while the SAR (Single Aliquot Regenerative Dose) procedure requires a disc. Therefore, in case where there is not adequate amount of sample (NSB4), SAR method should be preferred. 
The equivalent doses were measured using the MAAD protocol for sherds.

The steps of MAAD procedure are as follows:

- Twenty discs were prepared and divided into four groups, i.e. five discs for each group.

- The aliquots were normalized (using a short shine of $0.2 \mathrm{~s})$.

- One group was reserved for measurement of the natural IRSL.

- The growth curve was built from four points: Natural $(\mathrm{N}),(\mathrm{N}+3),(\mathrm{N}+8),(\mathrm{N}+13) \mathrm{Gy}$.

- All the discs irradiated were left for $24 \mathrm{~h}$ before luminescence measurements.

- Each data point represents the mean value of the measurements for five discs.

- The complete IRSL signal (130 s) was measured.

- Before normalization and measurements, all aliquots were subjected to preheating. The preheat temperature is $205^{\circ} \mathrm{C}$ for $3 \mathrm{~min}$.

The equivalent doses were measured using the SAR protocol for the soil sample.

The steps of SAR procedure are as follows:

- Three aliquots were prepared.

- First, the first aliquot was preheated and the complete IRSL signal (130 s) was measured to define the initial signal level L (N).

- Second, the aliquot was irradiated for $\beta_{1}$ (3 Gy), left for $24 \mathrm{~h}$ and preheated.

- Third, the complete IRSL signal was measured to define the first regeneration signal level, $L\left(\beta_{1}\right)$.

Irradiation, preheat, measurement were repeated for 9 and $15 \mathrm{~Gy}$. The line for this aliquot was plotted against the laboratory dose-luminescence signal and then the equivalent dose (ED) is calculated. The whole procedure was repeated for each aliquot.

\section{TL}

The ED was measured by integrating the TL curves between $330^{\circ} \mathrm{C}$ and $450^{\circ} \mathrm{C}$. For example, this temperature interval was determined by means of a plateau test (Aitken, 1985). The plateau test was done to decide which peaks to use for dating. By examining the glow curve, low temperature peaks were eliminated within TLD reader at $205^{\circ} \mathrm{C}$ for 3 minutes. The steps of MAAD procedure to be used to measure ED are as follows:

- Sixteen discs were prepared and divided into four groups, i.e. four discs for each group. Weight normalization was performed.

- The growth curve was built from four points: Natural $(\mathrm{N}),(\mathrm{N}+3),(\mathrm{N}+8),(\mathrm{N}+13)$ Gy.

- All the discs irradiated were left for $24 \mathrm{~h}$ before luminescence measurements.

- A disc was placed on a controlled heated tray $\left(5^{\circ} \mathrm{C} / \mathrm{s}\right)$ and the TL was integrated in the temperature interval $50-500^{\circ} \mathrm{C}$. Before measurements, all aliquots were subjected to preheating.

- The preheat temperature is $205^{\circ} \mathrm{C}$ for $3 \mathrm{~min}$.

- Each disc has been measured for two times. Truth TL counts have been obtained by subtraction of second data from first data.

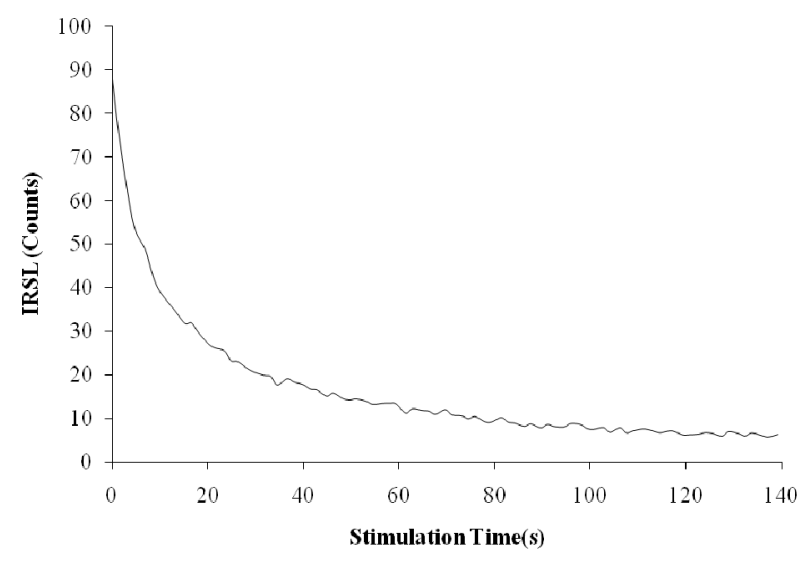

Fig. 2. Infrared-stimulated IRSL decay curve from NSB1. The bleach time of the sample (for natural dose) is specified from this graph.

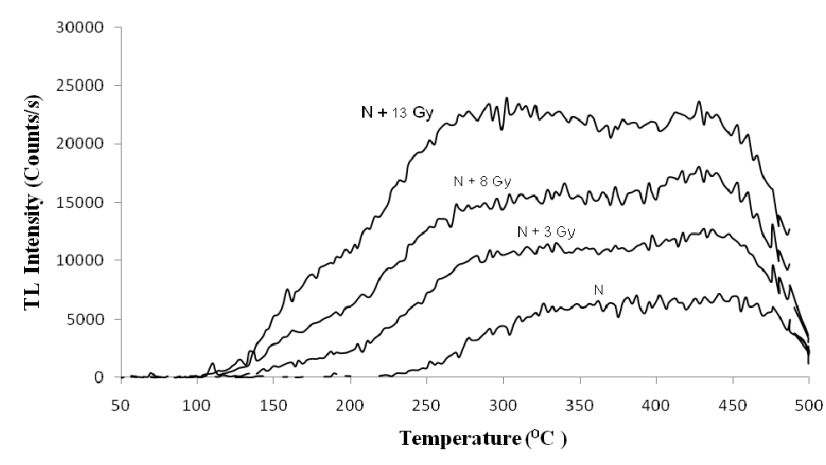

Fig. 3. $T L$ glow curves (subtracted background, $R T=5^{\circ} \mathrm{C} / \mathrm{s}$ ) from sample NSB2.

The growth curves were drawn and ED calculated by extrapolation to the dose axis. The supralinearity correction was determined with samples annealed for two hours at $400^{\circ} \mathrm{C}$; a beta regeneration growth curve was constructed using TL signals measured after the irradiation with three different known doses. $\beta$-source $(0.0323 \mathrm{~Gy} / \mathrm{s}$ on aluminum) was used for irradiation (Aitken, 1985).

\section{RESULTS AND DISCUSSION}

The typical IRSL decay curves and TL glow curves from sample NSB1 and sample NSB2 are depicted in Fig. 2 and Fig. 3, respectively. To calculate the equivalent dose, MAAD method was used and the graphs of additive dose versus luminescence counts were plotted. They are shown in Fig. 4. The fitting-line of the graphs was found to $\quad$ be: $\quad \mathrm{y}=9.0341 \mathrm{x}+64.518, \quad \mathrm{y}=2511.3 \mathrm{x}+18948$, $\mathrm{y}=2.4257 \mathrm{x}+21.211, \mathrm{y}=3.4625 \mathrm{x}+23.888$.

It is a known fact that the intercept with the IRSL intensity $=0$ axis ( $x$-axis) gives the equivalent dose. Thus, equivalent doses of NSB1 were determined through TL and IRSL to be $7.98 \pm 0.40 \mathrm{~Gy}, 7.55 \pm 0.38 \mathrm{~Gy}$, respectively. Equivalent doses of NSB2 and NSB3 were determined through TL $9.58 \pm 0.48$ Gy and $7.74 \pm 0.39$ Gy, respectively.

Based on the SAR procedure, the graphs of dose versus luminescence counts were plotted. These are shown in Fig. 5. The method interpolates the natural lumines- 
(a)

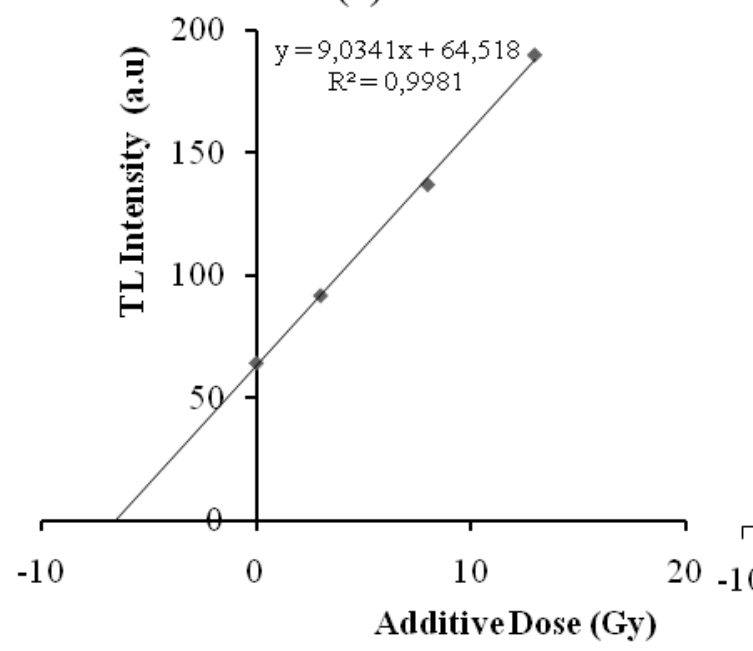

(c)

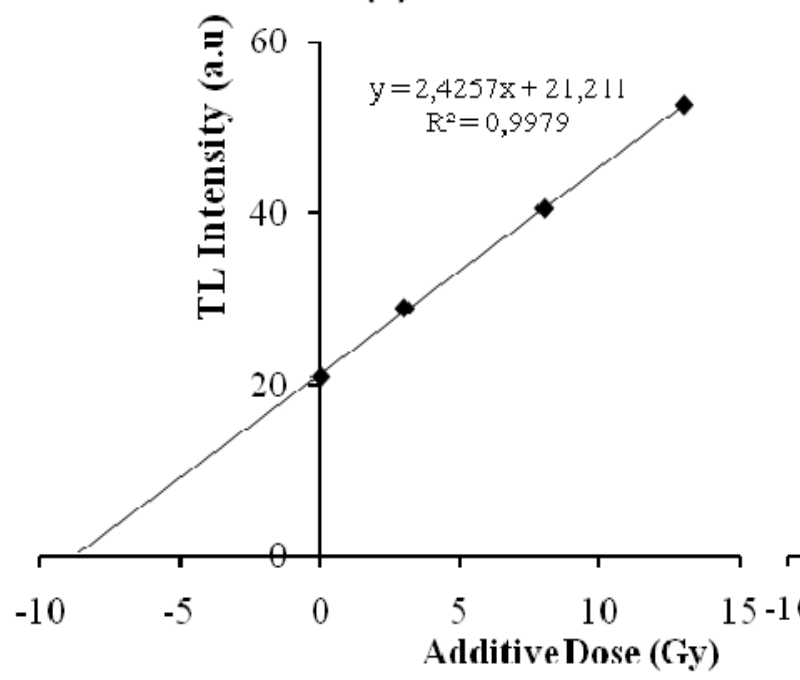

(b)

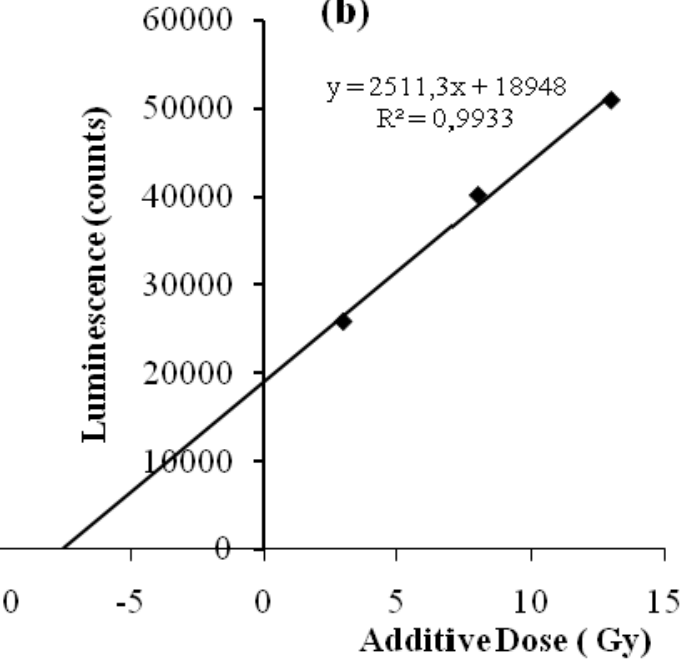

(d)

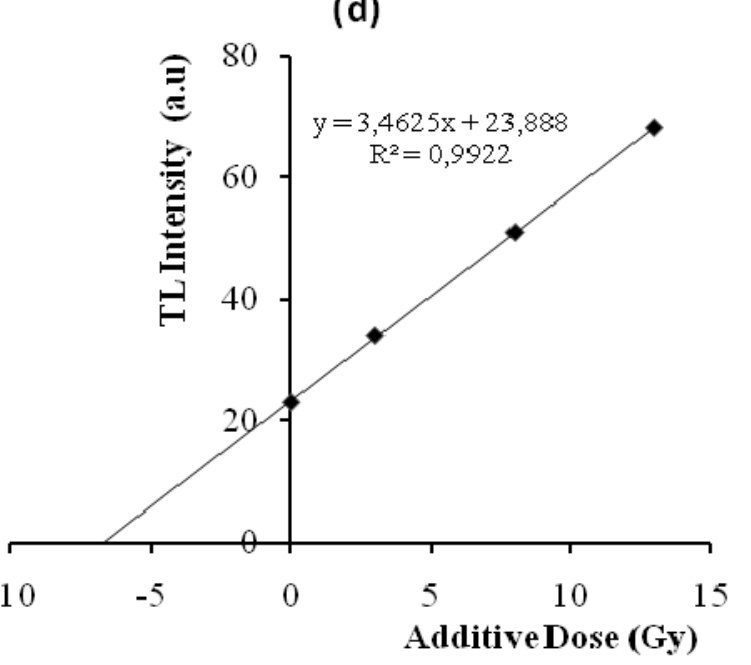

Fig. 4. Luminescence counts (integrated counts in 130 seconds for IRSL and integrated counts between $330^{\circ} \mathrm{C}-450^{\circ} \mathrm{C}$ for $T L$ ) versus additive dose using (a) TL for NSB1, (b) IRSL for NSB1, (c) TL for NSB2, (d) TL for NSB3. The intercept of the extrapolated line on the horizontal axis gives the paleodose.

cence signal onto a growth curve. The ED values of NSB4 obtained using three discs were found as $8.82 \pm 0.44 \mathrm{~Gy}, 8.67 \pm 0.43 \mathrm{~Gy}, 8.42 \pm 0.42$ Gy respectively, (Fig. 5. a, b, c). It is clear that the results obtained are satisfactorily in agreement with each other. The average ED was found as $8.64 \pm 0.43 \mathrm{~Gy}$.
Radioactivity values and polymineral IRSL ages are given in Table $\mathbf{1}$ and Table 2, respectively. Ages of NSB1 were found through TL and IRSL to be $2333 \pm 169$ a and $2208 \pm 160$ a respectively. Ages of NSB2, NSB3 were found through TL to be $2568 \pm 187$ a, $2389 \pm 172$ a respectively and age of NSB4 was found through IRSL to be $2440 \pm 170$ a.

Table 2. Ages determined for pottery sherds and soil sample.

\begin{tabular}{lllll}
\hline Sample & Method & Equivalent Dose(Gy) & Annual Dose(mGy/a) & Age(a) \\
\hline NSB1 & TL & $7.98 \pm 0.40$ & $3.42 \pm 0.18$ & $2333 \pm 169$ \\
& IRSL & $7.55 \pm 0.38$ & $3.42 \pm 0.18$ & $2208 \pm 160$ \\
NSB2 & TL & $9.58 \pm 0.48$ & $3.73 \pm 0.20$ & $2568 \pm 187$ \\
NSB3 & TL & $7.74 \pm 0.39$ & $3.24 \pm 0.17$ & $2389 \pm 172$ \\
NSB4 & IRSL & $8.64 \pm 0.43$ & $3.55 \pm 0.17$ & $2440 \pm 170$ \\
\hline
\end{tabular}



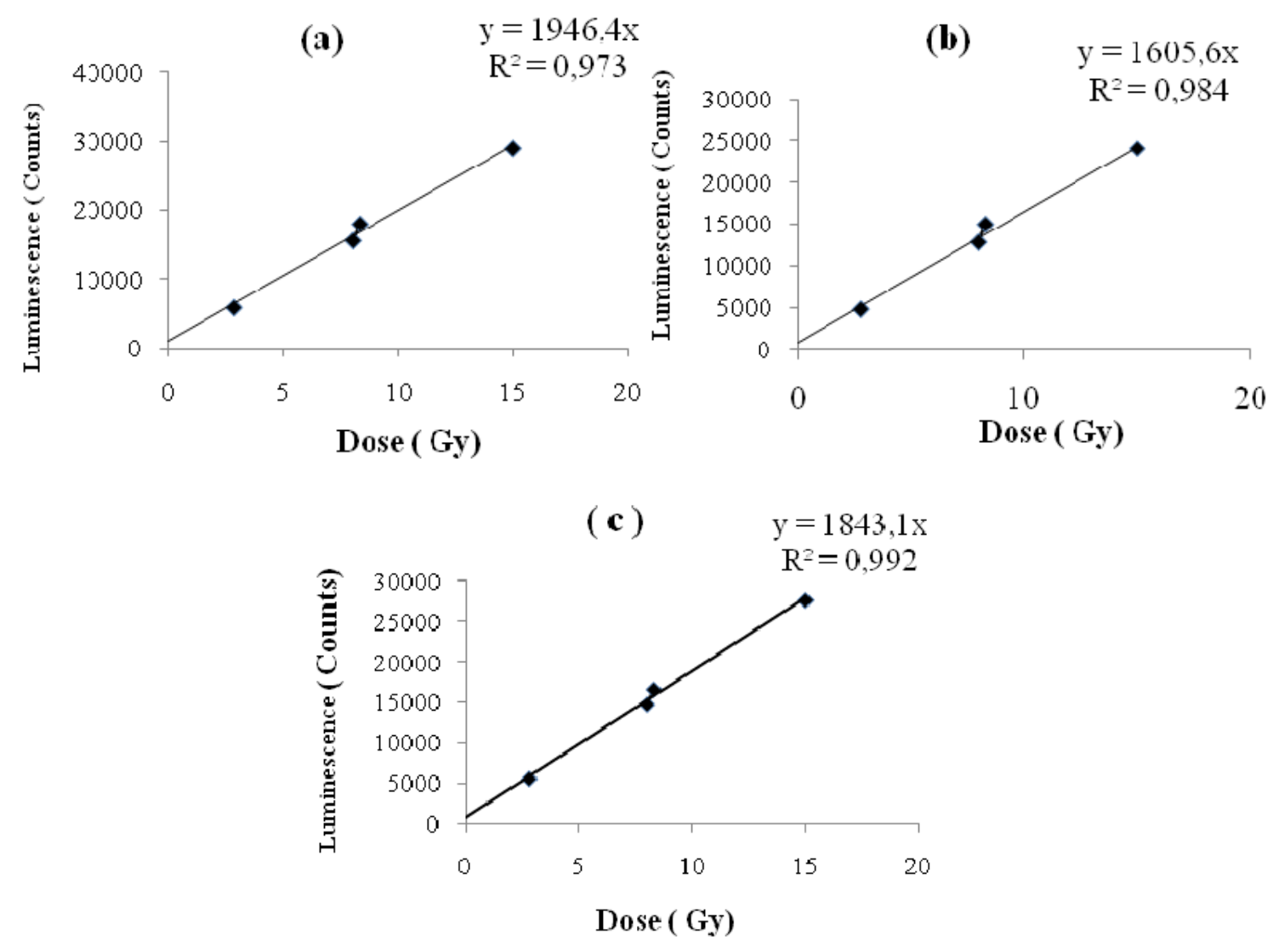

Fig. 5. (a), (b), (c) Growth curves used in determination of ED for three discs of NSB4 by using SAR procedure.

\section{CONCLUSION}

Based on Table 2, it can be concluded that IRSL of equivalent dose was roughly close to that of TL for NSB1. So it is reasonable to conclude that both results of IRSL and TL were in agreement for the known ages of the sherds in authenticity level. The average value of these measured annual doses is $3.45 \mathrm{mGy} / \mathrm{a}$. Since the ages of sherds are roughly close, it can be considered that they belong to same pottery. It can be concluded that archaeological potteries can also be dated successfully by IRSL and TL technique. Since the age of the NSB4 soil sample which adhered to surface of human bone is in agreement with the ages of the NSB1, NSB2, NSB3 pottery sherds, we concluded that this age indicates the date of burial. We believe that this case study can contribute to dating investigations and soil sample which adhered to surface of human bone can be used in IRSL sediment dating especially when the availability of datable material is limited in a Necropolis.

The obtained ages indicate Hellenistic period. Hellenistic period at the site is from $330 \mathrm{BC}$ to $33 \mathrm{AD}$ (Bartl, 1993; Burney, 1985). Furthermore, architecture of castle wall, Necropolis and column sherds in the vicinity of the site also indicates Hellenistic period. Consequently, the results were in a good agreement with the other archaeological evidences.

One of the conclusions of the study is that the dating of the tomb, the ancient fort and the roads leads to these structures points to the use of these structures during the
Hellenic and Roman era. Therefore, moral as well as scientific obligation falls upon the scientific community to further study the remaining seven un-opened tombs.

\section{ACKNOWLEDGEMENTS}

This work was supported by the Scientific and Technical Research Council of Turkey (TUBITAK) [T-BAG- 108T042].

We want to thank Z. Michael Islek for English grammar checking.

\section{REFERENCES}

Aitken MJ, 1985. Thermoluminescence Dating. London, Academic Press: $359 \mathrm{pp}$.

Aitken MJ, 1998. An introduction to optical dating. Oxford, Oxford University Press: 267 pp.

Atlıhan MA and Meriç N, 2008. Luminescence dating of a geological sample from Denizli, Turkey. Applied Radiation and Isotopes 66: 69-74, DOI 10.1016/j.apradiso.2007.07.020.

Bartl K, 1993. Some Remarks on the Early Iron age in Eastern Anatolia. Anatolica 21: 205-212.

Burney CA, 1958. Eastern Anatolia in the Chalcolithic and Early Bronze Age. Anatolia Studies 30: 157-167.

Kiyak NG and Erturaç MK, 2008. Luminescence ages of feldspar contaminated quartz from fluvial terrace sediments. Geochronometria 30: 55-60, DOI 10.2478/v10003-008-0007-8.

Madsen AT and Murray AS, 2009. Optically stimulated luminescence dating of young sediments: Geomorphology, DOI $10.1016 / \mathrm{j}$. geomorph.2008.08.020. 
Moska P, Bluszcz A, Poręba G and Wiszniowska A, 2008. Combined IRSL/OSL Dating on Fine Grains from Lake Baikal Sediments. Geochronometria 31: 39-43, DOI 10.2478/v10003-008-0018-5.

Spooner NA., Aitken MJ, Smith BW, Franks M and McElroy C, 1990. Archaeological dating by infrared-stimulated luminescence using a diode array. Radiation Protection Dosimetry 34: 83-86.

Senyurt SY, 2006. Büyükardıç; an early iron age hilltop settlement in Eastern Anatolia Ankara, Gazi University, Research Center for Archaeology Press: 38 pp (in Turkish).

Tanır G, Meriç N, Aytekin H and Okuducu Ş, 2004. A fitting procedure for palaedose from old sandstone using IRSL. Czechoslovak Journal of Physics 54: 941-946.
Vieillevigne E, Guibert P and Bechtel F, 2007. Luminescence chronology of the medieval citadel of Termez, Uzbekistan: TL dating of bricks masonries. Journal of Archaeological Sciences 34: 14021416, DOI 10.1016/j.jas.2006.10.030.

Zink A, 2008. Uncertainties on the luminescence ages and anomalous fading. Geochronometria 32: 47-50, DOI 10.2478/v10003-0080027-4.

Zuchiewicz W, Cuong NQ, Bluszcz A and Michalik M, 2004. Quaternary sediments in the Dien Bien Phu fault zone, NW Vietnam: a record of young tectonic processes in the light of OSL-SAR dating results. Geomorphology 60: 269-302, 10.1016/j.geomorph.2003.08.004 